\title{
Apología y crítica de la ciencia en Edgar Morin: una búsqueda antropológica
}

\author{
Ricardo Guzmán Díaz
}

\section{INTRODUCCIÓN}

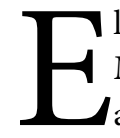
1 interés por las ciencias naturales que Edgar Morin revela en su obra no es accidental, su aparición no es meramente circunstancial, sino que responde a lo más profundo de sus preocupaciones. En el prólogo de Ciencia con consciencia nos explica cómo desde su primer libro, El hombre $y$ la muerte, el problema que lo acompañará toda la vida es "el de una antropo-sociología abierta [...] al universo biofísico, del cual se distingue al mismo tiempo que está inmersa en él" (Morin, 1984: 9). Para Morin la preocupación antropológica no puede prescindir de una reflexión sobre temas científicos fundamentales, como la relatividad einsteiniana, la teoría del big bang, el principio de indeterminación de Heisenberg, entre otros, pues el hombre es, después de todo, hijo del cosmos. De esta manera surge en él un diálogo multidisciplinario con el que se verá en posición de cuestionar los aspectos del mundo contemporáneo al identificar sus problemas y sus crisis.
A pesar de su temprana relación con las ciencias naturales, fue gracias a una invitación que recibió para una estancia en el Instituto Salk de Estudios Biológicos, entre 1969 y 1970, que Morin hace un contacto más directo con las teorías más recientes que se discutían en ese entonces en los campos de la física, la biología, la genética, etc. Esta oportunidad, combinada con su excepcional formación en ciencias humanas, lo llevaría a proponer su paradigma de la complejidad constituido en torno a los conceptos de orden, desorden y organización con los que tratará de entender el entramado de la realidad.

En diferentes momentos, Edgar Morin reconoce el poder de la ciencia de la naturaleza nacida en la cultura occidental, señala sus posibilidades y sus límites, puntualiza sus errores, identifica las rupturas que experimenta durante el siglo xx y nos descubre nuevos caminos que nos permiten superar una visión del mundo que nos quedó corta. Morin escudriña una nueva manera de entender la ciencia, más trascendente, que abarque la complejidad humana y que no se quiebre en la sobreespecialización que mutila y

Defense and Critique of Science in Edgar Morin: An Anthropological Search

\author{
Ricardo Guzmán Díaz: Investigación en Ciencia y Cultura, Instituto Tecnológico y de Estudios Superiores de Monterrey, \\ Monterrey, Nuevo León, México \\ rguzman@itesm.mx
}

Desacatos, núm. 40, septiembre-diciembre 2012, pp. 143-156 
dispersa el conocimiento. Se afana por encontrar un pensamiento totalizador - que no totalizante, explica él-, ${ }^{1}$ un conocimiento más amplio y reflexivo. Para arribar a tal concepción considera que el aporte de las ciencias es tan importante, que a partir de ahí construirá su paradigma de comprensión. La búsqueda "viene de nuestro suelo científico en convulsión [...] ha nacido de la crisis de la ciencia, y se nutre de sus progresos revolucionarios" (Morin, [1981] 2006a: 30). El presente ensayo busca recuperar y valorar, en su justa medida, la visión moriniana de las ciencias naturales, así como atender su demanda por evadir la tentación de la simplicidad y por admitir que nada en nuestro mundo puede ser estudiado de manera transparente y objetiva, que siempre encontraremos complejidad, diversidad, caos.

\section{CIENCIAY CIVILIZACIÓN OCCIDENTAL}

Según Morin, la aventura intelectual que dio lugar a miento cartesiano, pero su desarrollo posterior estuvo marcado por una serie de paradojas, de incongruencias, de contrasentidos. El establecimiento de reglas, métodos y heurísticas permitieron un desarrollo insólito de las ciencias, pero en su camino tuvo que recurrir, en varios sentidos, al ocultamiento, a la disyunción, a la fragmentación. Fue un proceso necesario en su momento, pero que en el último siglo ha debido reconsiderar sus puntos de partida, los supuestos en los que se basó, gracias a lo cual presenta ahora opciones nuevas, miradas renovadas que apuestan a una transformación enriquecida de nuestra visión del mundo. Un nuevo atisbo que, desde la perspectiva de Morin, lleva en su núcleo la idea de complejidad y con ella las de orden, desorden, incertidumbre, azar y organización.

\footnotetext{
${ }^{1}$ Se trata, más que de un sistema de pensamiento globalizador, de una forma de reflexión que articule, de un "esfuerzo [que conduzca] a los conocimientos cruciales, los puntos estratégicos, los nudos de comunicación [...] entre las esferas disjuntas" (Morin, [1981] 2006a: 33).
}

En René Descartes (1596-1650) reconocemos gran esfuerzo y voluntad por encontrar un método riguroso, asentado sobre bases indiscutibles y guiado por la razón, que nos condujera a un conocimiento cierto, transitando de una "filosofía especulativa" a una "práctica mediante la cual, conociendo la fuerza y las acciones del fuego, el agua, el aire, los astros, los cielos y todos los demás cuerpos que nos rodean", pudiéramos emplearlos y “convertirnos así en una especie de dueños y poseedores de la naturaleza" (Descartes, [1637] 1998: 74). ¿Quién habría imaginado el alcance de este sueño? ¿Quién habría conjeturado que a partir del punto de quiebre establecido por Descartes y sus contemporáneos - Bacon, Galileo, etc.- se llegara a conocer la estructura más íntima de la materia, los secretos del espacio-tiempo, los orígenes del cosmos, la estructura y codificación de la vida, las complejas operaciones del cerebro? Sin embargo, nos dice Morin, después de un largo andar, hemos extraviado el sueño de constituir una visión del hombre y del mundo. Si bien el investigador especializado contemporáneo cuenta con recursos impensables de conocimiento, de herramientas y de métodos, al ser dueño de sólo una pequeña parcela de la realidad, la posibilidad de dicha visión global e integral se ha visto sustituida por otro tipo de motivaciones bajo la perspectiva de que:

el saber no es producido para ser articulado y pensado, sino para ser capitalizado y utilizado de manera anónima. Las cuestiones fundamentales son rechazadas como cuestiones generales, es decir, vagas, abstractas, no operacionales. La cuestión original que la ciencia arrebató a la religión y a la filosofía para asumirla, la cuestión que justifica su ambición de ciencia: ¿qué es el hombre, qué es el mundo, qué es el hombre en el mundo?, la remite [...] a los no sabios, descalificados a priori. Sólo tolera que, a la edad de retirarse, sus grandes dignatarios adopten cierta altura meditativa (Morin, [1981] 2006a: 25).

En otras palabras, la ciencia se manifiesta en su incapacidad para articular el conocimiento, dislocado ahora "en mil saberes ignorantes", sin posibilidad de concebirse a sí misma y sujeta a poderes de 
manipulación, de sojuzgamiento, algunos visibles, otros subrepticios. Para Morin, se trata de la amenaza de una época oscura en la que:

nos acercamos a una temible revolución en la historia del saber, en la que éste, dejando de ser pensado, meditado, reflexionado, discutido por los seres humanos, integrado en la búsqueda individual del conocimiento y de sabiduría, resulta estar destinado cada vez más a ser acumulado en los bancos de datos, y después computado por instancias manipuladoras, en primer lugar, el Estado (Morin, 1984: 33).

Son las dos caras del dios Jano, que aparecen como dos vertientes del proyecto de la Ilustración. Por un lado, un progreso inaudito de los conocimientos, del poder de la ciencia y de sus aplicaciones benéficas a la sociedad en campos tan diversos como la salud, las comunicaciones, etc. Por otro lado, tenemos un aspecto fallido, un camino desviado, una historia que nos ha llevado a tiempos de sometimiento del ser humano a un conjunto de poderes de carácter tecnoeconómico que pretenden legitimarse en la razón científica. Se trata de la conformación de un mundo en el que la capacidad y la acción humanas son minimizadas a esferas de puro trabajo técnico bien organizado, de efectividad administrativa para el logro de intereses particulares. En pocas palabras, una forma de vida que al final deja vacío el espíritu humano. Todo bajo el cobijo de una racionalidad cuyo basamento ontológico radicaba en los principios lógicos de identidad y de no contradicción (Morin, [1992] 2006d: 178-179). Pero, a más de decir que la ciencia del siglo xx tendrá que negar la absolutización de estos principios, Morin dirige su

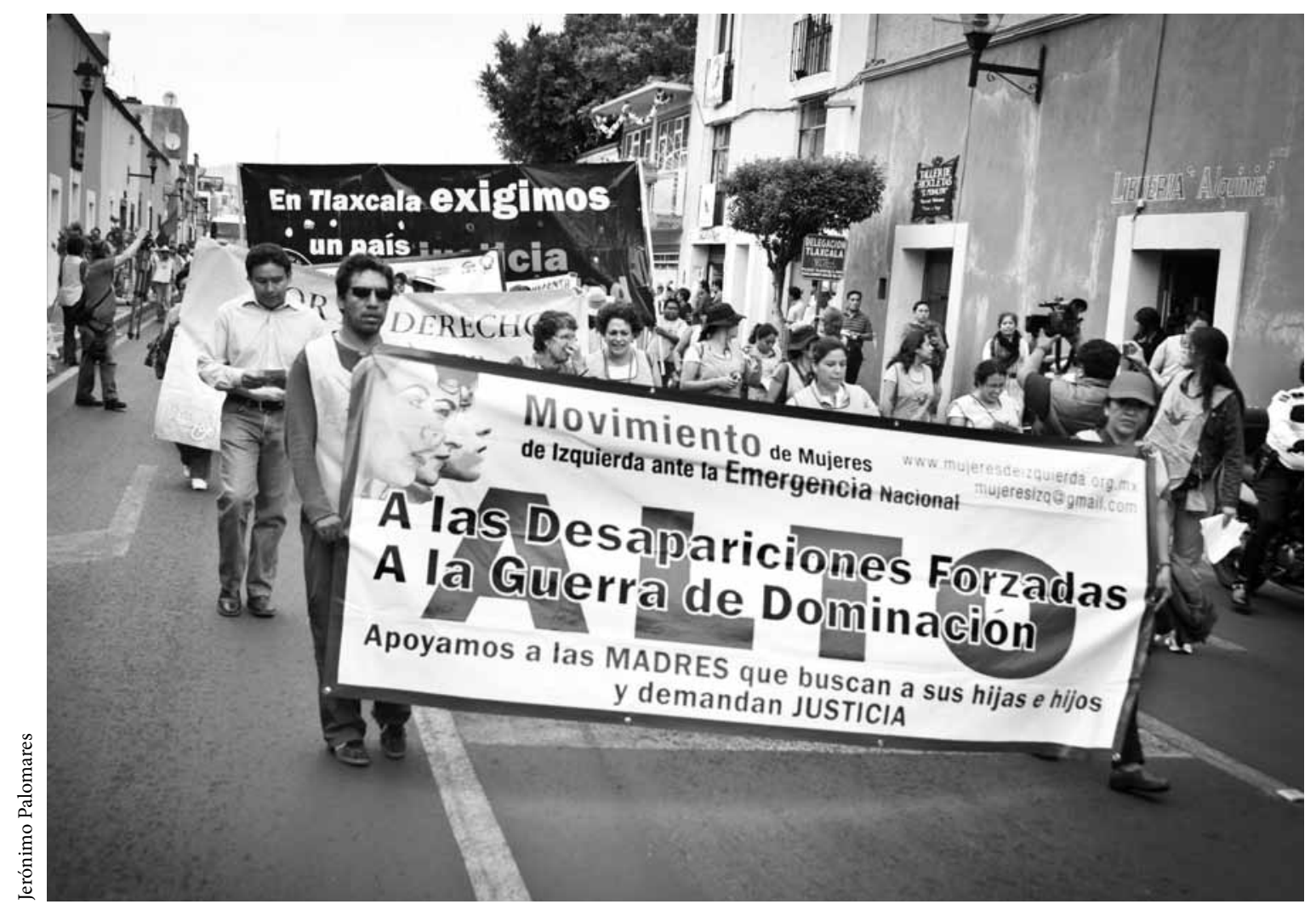

Manifestación contra la violación de los derechos de la mujer, 2012. 
crítica a la conversión de dicha racionalidad en una racionalización que pretende "encerrar la realidad en el orden y la coherencia de un sistema" (Morin, [1981] 2006a: 35) o una racionalización justificante de la explotación y en perjuicio de lo que en principio era una de las motivaciones del pensamiento racional: la emancipación del ser humano.

Edgar Morin pone sobre la mesa el hecho, quizás trivial para algunos, aunque tal vez no para los propios estudiosos de la naturaleza, de que la ciencia occidental es una elección sobre una forma de mirar al mundo y de comprendernos a nosotros mismos y que lleva implícitamente una serie de dogmatismos, ataduras y carencias. Una breve revisión histórica nos puede revelar algunos de estos elementos. Si bien hablábamos de Descartes como punto de quiebre, en realidad suele ubicarse el nacimiento de la racionalidad occidental en la civilización griega, en la que se enfrenta por primera vez el problema cosmológico sin recurrir a los dioses, es decir, naturalizando la relación entre el hombre y su entorno: la búsqueda de Merecen mención especial las ciencias griegas más desarrolladas. Nos referimos fundamentalmente a las matemáticas - en especial la geometría- y la astronomía. La geometría nos presenta una matemática de formas estáticas, permanentes y de relaciones lógicas - los "Elementos" de Euclides-. Recordemos que para Aristóteles el universo está dividido en dos regiones: la supralunar, donde todo es perfecto, estable, sin cambio, y la sublunar, donde todo cambia, se degrada, se corrompe, Así, los cielos son perfectos, están hechos de un quinto elemento. Su permanencia y estabilidad permiten hacer una ciencia de los cielos, basada en paradigmas geométricos, los astros moviéndose en círculos que giran sobre otros círculos pero que permanecen eternamente en su estado de perfección. Es la permanencia del ser que encontramos en la filosofía de Parménides. Por otro lado tenemos el continuo cambio y devenir de las cosas, el "todo fluye" de Heráclito como contraparte. Entonces, ¿cómo hacer ciencia del mundo sublunar, donde todo cambia? Para esto habría que esperar la llegada de

otra matemática, la del cálculo diferencial —-después de un sueño de 1500 años en que había retornado y se había instalado la hegemonía de lo sagrado- que permitiría tratar el flujo del tiempo - "fluxiones" para Newton- y unir los momentos instantáneos en un proceso dinámico. Para esto debería conservarse de alguna forma la idea de permanencia - de nuevo el ser-, ya no como algo estático, pero sí como la presencia de regularidades en ese devenir -leyes físicas- La ciencia moderna, aunque de manera quizá más oculta, se queda con el ser como la única forma de aferrarnos a lo estable para dar luz a nuestro entendimiento, bajo la inteligibilidad de un mecanicismo cuyo máximo exponente sería Newton. En esta renovada cosmovisión, "el nuevo Universo se convertía en una mecánica perfecta que obedecía a las Leyes fijadas por un Dios-Monarca absoluto" (Morin, [1992] 2006d: 60).

En la historia se revelan las determinaciones, las elecciones que condujeron a la ciencia moderna y, por ende, sus constreñimientos e insuficiencias. El método y su lógica implican la selección misma de los datos y las variables que se consideran relevantes para afirmar la coherencia de una teoría y la exclusión de aquello que es obstáculo para su certificación. Este proceso es guiado a su vez por procesos más profundos. Morin nos habla de paradigmas, en un sentido más radical que Kuhn, como "principios ocultos que gobiernan nuestra visión de las cosas y del mundo sin que tengamos conciencia de ello" (Morin, [1990] 2007: 28). La ciencia moderna se desenvolvió bajo el paradigma de la simplificación. El origen, como explicábamos, está en Descartes. Para evitar el error habría que dividir lo examinado en sus partes simples y partir de la comprensión de dichas partes para posteriormente reunirlas en su totalidad. Paradigma reduccionista con la ilusión de una "verdad" definida por la posibilidad de expresión de ideas claras y distintas, que junto a la cuantificación y matematización del conocimiento proporcionaría éxitos inimaginables, teorías comprensivas con alcances de predicción que permitirían no sólo modelos explicativos de los fenómenos, sino su posibilidad de control. 
Manipulación y control aparecen como objetivos que como parte del paradigma de simplificación llevan a la reducción de todas las causas aristotélicas a la causa eficiente, ligada al establecimiento de conexiones causa-efecto y, si no a eliminar, al menos a minimizar las causas material, formal y final. Lo que importaba era una formalización efectiva de las relaciones, aunque se sacrificaran elementos de comprensión. Esta forma de reducción queda claramente expresada por Richard Feynmann cuando señala que "a los físicos les gusta pensar que todo lo que hay que decir es ésas son las condiciones, ahora ¿qué pasa después?" (Feynmann, citado por Gleick, 1988: 9).

Ahora bien, en esta forma de racionalidad inaugurada por los griegos y reconfigurada en la revolución científica se presenta una ruptura que permeará los modos de comprensión y de relación con el mundo de la civilización occidental: la separación entre sujeto y objeto. El reconocimiento de que el fenómeno del conocimiento incluye a los dos, pero a la vez de que para lograr el conocimiento "verdadero", aquel que refleje como en un espejo la realidad del objeto, el sujeto deberá apartarse y ser rechazado de la ciencia, pues el mundo que está "ahí afuera" es aparentemente autosuficiente y existe objetivamente independiente del sujeto. Pero "el gran misterio [es que] la objetividad científica deba necesariamente aparecer en el espíritu de un sujeto humano", nos dice Morin ([1990] 2007: 67). Se trata del problema irresuelto de la dualidad mente/cuerpo, relacionado irremediablemente con el problema de la flecha del tiempo. En su libro The Emperor's New Mind, Roger Penrose (1989) nos recuerda que en la imagen que nos ofrece la física clásica no hay lugar para el pensamiento y, podemos agregar, no hay lugar para la distinción entre pasado y futuro. Sus leyes nos marcarían, en su carácter determinístico, todo lo que ha sido y todo lo que será. La ciencia clásica se olvidó del elemento esencial de la experiencia humana pensante que es la existencia de un "antes" y un "después", es decir del flujo del tiempo. Así, aparece una grieta más en nuestra comprensión de la realidad: por un lado, las ciencias de la realidad material - ciencias naturales-, por otro, las ciencias de la experiencia y del fenómeno humano - ciencias del espíritu-. Una fragmentación, señalada por Snow (1964), que perdura hasta nuestros días. ${ }^{2}$

Desde la perspectiva de Morin, hablamos de un conocimiento con carencias y parcelado. Esto último evidenciado por el carácter disciplinar de la ciencia moderna, en la que, para fines prácticos, la posibilidad de pensar el sentido global del conocimiento queda vedada a un investigador, so pena de descuidar su área de especialidad. La articulación entre zonas del conocimiento intenta remediarse por reducción: de lo humano a lo biológico, a lo químico, a lo físico. Y junto a esto el ideal de un orden perfecto, el sueño de desentrañar el universo en términos de una operación mecánica perfectamente descrita y articulada. Un todo formado por partes, cada una independiente, pero perfectamente engranada con el resto formando la maquinaria del cosmos.

Morin nos advierte: a la par de los enormes progresos surgirán consecuencias extremadamente nocivas que saldrán a la luz hasta el siglo xx. Junto a la capacidad de la ciencia para dilucidar, manipular y penetrar los misterios de la naturaleza, "se han operado deslizamientos y permutaciones de finalidad: el medio - la manipulación - ha llegado a ser también fin $y$, al manipular para experimentar, se ha experimentado para manipular" (Morin, [1981] 2006a: 412). Encontramos la simiente desde el siglo XIX, durante el que no fue casual que la cultura industrial y la cultura científica tuvieran una convergencia como empresas sociales ambas, bajo el mandato de la transformación de las fuerzas naturales con el fin de extraer el poder que ahí se ocultaba y manifestarlo de múltiples formas, especialmente en su conversión en movimiento y trabajo útil. La física de finales del siglo xIX nos hablaba de una economía de la

\footnotetext{
${ }^{2}$ Snow se refirió en realidad a las ciencias y a las letras. Presentó sus ideas en una conferencia en 1959 titulada "The Two Cultures", y las extendió en 1964 bajo el título The Two Cultures: And a Second Look.
} 


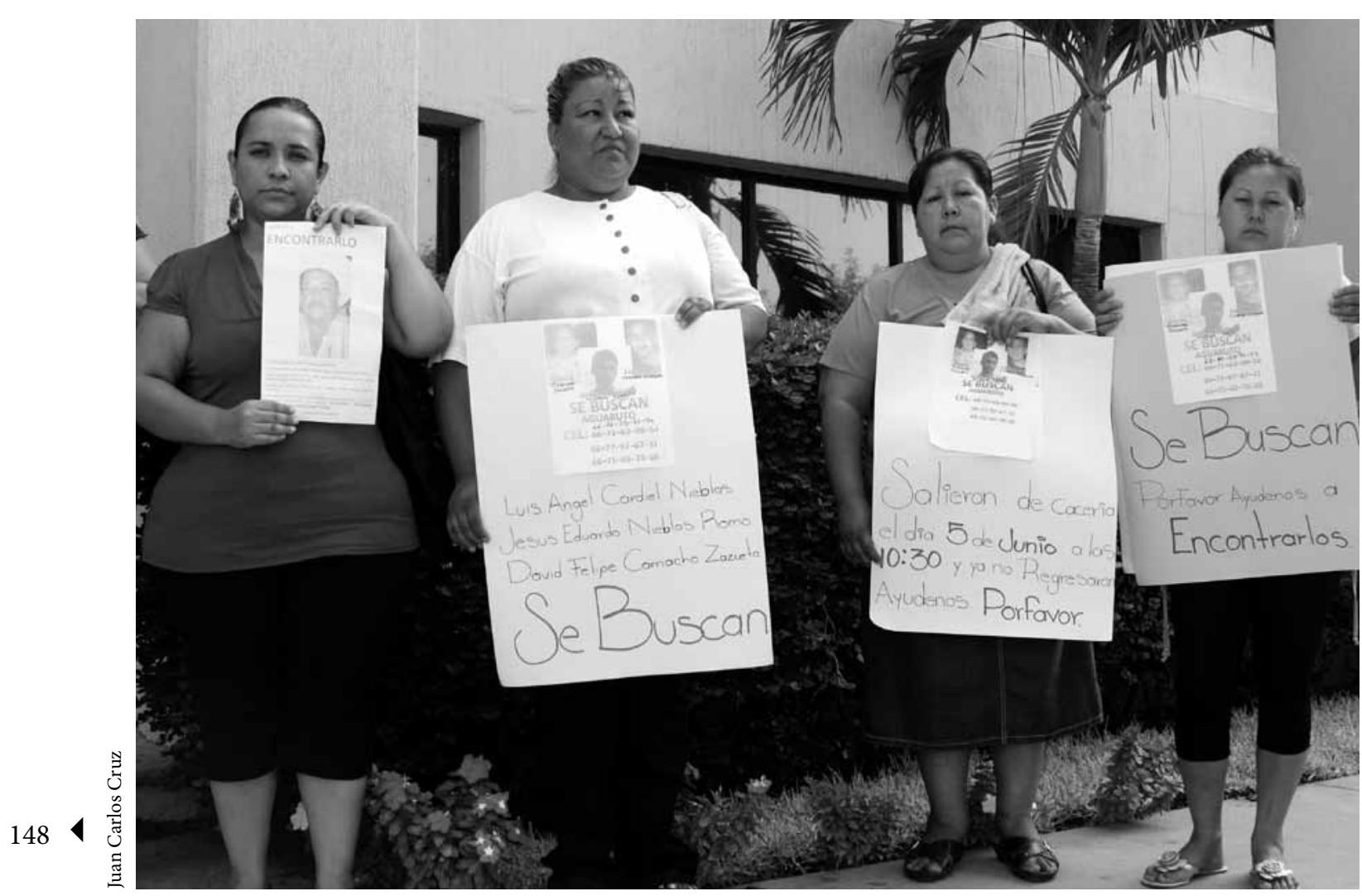

Organismos civiles y la sociedad en general se han manifestado en varias ocasiones contra la violencia que ha generado la guerra contra el narco, 2011.

naturaleza, que poseía riquezas que podían producir trabajo útil por medio de máquinas que aprovecharan dichos recursos. La Revolución Industrial había fraguado una nueva cultura del trabajo, que pugnaba por la eficiencia en los procesos de producción de bienes. Ahora, gracias al trabajo científico, la misma idea podía transferirse tanto a las operaciones de la naturaleza como a las de las máquinas. Se trataba de una cultura de la eficiencia que pedía la optimización de las máquinas, pero que también exigía lo mismo de los hombres. El conocimiento científico se torna prolífico y eficaz y esas cualidades le permiten integrarse a las diversas instituciones representativas del poder: el Estado, la industria, el ejército. Morin nos señala las paradojas del proceso: al autonomizarse, [las ciencias naturales] resultaron cada vez más profundamente interdependientes de un proceso en adelante científico-técnico-económicosocial [...] el conocimiento científico es cada vez más puro, desinteresado, especulativo, pero al mismo tiempo es cada vez más operacional, manipulador y manipulado.

Ciencia, técnica, sociedad han devenido sustentadoras y sustentadas en un torbellino en el que son mutuamente dominadoras y dominadas, sojuzgadoras y sojuzgadas. Este torbellino afecta en adelante al devenir del planeta. Se acelera una aventura fantástica en la que la ciencia, cada vez más alucinante y ciega, omnipotente e impotente, se ha convertido en cabeza investigadora. No hace un siglo se creía que conducía a la emancipación de la humanidad. Hoy vemos que puede conducir al sojuzgamiento del hombre y a la explosión del mundo. Nada está decidido todavía (Morin, [1992] 2006d: 62-63). 
Morin se pregunta sobre el futuro de nuestra civilización, sobre el posible paso a una sociedad-mundo (Morin, [2003] 2006e: 264). La principal barrera para superar un momento de crisis que puede llevarnos bien a la autodestrucción, bien a una nueva etapa para la humanidad, es una forma de pensamiento incapaz de concebir lo global y lo fundamental, que sólo conoce el cálculo y desconoce a los individuos. El mundo avanza vertiginosamente potenciado por cuatro motores entrelazados: la ciencia, la técnica, la industria y la economía capitalista (Morin, [2003] 2006e: 269). El desenlace es incierto.

\section{NUEVOS HORIZONTES}

La ciencia nacida de la revolución científica, que alcanzara su profesionalización y su mayoría de edad durante el siglo xIX, vería en la primera mitad del siglo xx sus más consumados logros - liberación de la energía encerrada en las entrañas de la materia, el desciframiento del código de la vida, el desvelamiento de la estructura del universo etc. $-y$, al mismo tiempo, sufriría el desmoronamiento de muchos de sus cimientos. Sin embargo, las nociones que dieron lugar a esa crisis de fundamentos son las mismas que están permitiendo concebir nuevas formas de entendimiento. Los expulsados de la ciencia volverán triunfantes: el sujeto, lo complejo, el desorden, el azar, el espíritu, la libertad. Para Morin, las nuevas posibilidades de comprensión no son ruptura total, provienen del mismo esfuerzo de las ciencias nacidas con Descartes, pero con nuevas afinidades con la reflexión filosófica, con el compromiso de no ceder al pensamiento simplificador que idealiza, racionaliza y normaliza, y con la decisión firme de no temer al error, a la incertidumbre y al carácter siempre inacabado de nuestro conocimiento.

Morin nos recuerda por un lado el fracaso del positivismo lógico en su afán de encontrar los fundamentos del conocimiento cierto. Tanto la inducción como la deducción, nos dice Morin haciendo eco de Hume, Popper y Gödel, son insuficientes para afirmar a plenitud un conocimiento. Más aun si el conocimiento se presenta con este problema, ni qué decir del metapunto de vista que busque responder a la pregunta de cómo conocemos (Morin, [1988] 2006c: 22-27).

La avalancha que haría tambalear lo más preciado de la ciencia mecánica heredada de Newton: la idea del orden perfecto que mueve los engranes del universo, empezó sutilmente en la segunda mitad del siglo XIX en la ciencia de la termodinámica. En dicha ciencia se pone al descubierto por primera vez una contradicción oculta de la disposición perfecta del cosmos. Por un lado, el primer principio de la termodinámica revela como unidad fundamental de la naturaleza a la energía, sus posibilidades de transformación, pero sobre todo su indestructibilidad. Por otro lado, el segundo principio, revelado por Clausius, manifiesta una degradación de esa misma energía, produciendo una grieta en la explicación mecánica del universo. Cada proceso de transformación lleva consigo un desgaste, un desperdicio, una fracción de la energía que no desaparece y que queda inutilizable. El cosmos no es entonces un mecanismo indestructible, sino que está sujeto a un proceso que lo llevará a su "muerte". Boltzmann quiso darle justificación mecánica, pero llegó a una interpretación probabilística de lo que se llamó "entropía", variable física que representa el desorden al que lleva dicha degradación. Se había insertado, de una vez por todas, la flecha del tiempo y la problematización de la misma idea de orden.

Eso sólo sería el principio de un alud de nuevas nociones que cambiarían radicalmente nuestra visión del mundo. Morin, haciendo gala de su intuición físico-filosófica, nos revela con maestría el cambio profundamente ontológico que supone la nueva revolución que se da en la física a principio del siglo xx: por un lado el "desarreglo microfísico", por otro el "desorden genésico" o problema cosmológico, y que, a su juicio, marcará el nacimiento de una physis, de un estrato o simiente de la realidad radicalmente distinta (Morin, [1981] 2006a: 55-58). 
La nueva física nacida con Einstein, Planck, Bohr y toda una pléyade de pensadores hace estallar la materia. Si bien Rutherford quiso entender el átomo a imagen y semejanza de un sistema solar, con un núcleo material pesado en un centro orbitado por ligeros electrones, al final, las partículas fundamentales de que están hechas las cosas quedarán confundidas entre visiones corpusculares y ondulatorias, entre campos e interacciones. A decir de uno de los principales exponentes de la nueva física cuántica, la materia dejó de "ser algo permanente, perfectamente alcanzable [...] que nunca podría ser destruida [y que] se podía agarrar con la seguridad de que no se esfumaría entre los dedos" (Schrödinger, [1951] 1988: 22). La materia deviene en algo mucho más escurridizo y etéreo cuya identidad queda en entredicho. El principio de incertidumbre de Heisenberg borra la imagen de un mundo formado por entidades materiales cuyas interacciones y trayectorias están determinadas de manera objetiva de forma continua y con precisión matemática, y nos arrastra a la realidad. Desde entonces ya nada sería igual en nuestra concepción del mundo. La matemática seguirá siendo, quizás con más vehemencia, el lenguaje de la ciencia, pero ahora describirá probabilidades, fluctuaciones, azares. Más que materia, la partícula es forma, organización, pero también incertidumbre y fluctuación. Igual que con el segundo principio de la termodinámica, otra vez "el orden y la organización se hacen problema, devienen enigma" (Morin, [1981] 2006a: 56).

El siglo xx también vio nacer un universo en expansión. Encontramos su primera base empírica en el desplazamiento hacia el rojo que delata el alejamiento de las galaxias entre sí. De la misma manera que sabiendo que dos autos que se alejan de un punto de origen, uno viajando a $50 \mathrm{~km} / \mathrm{h}$ a una distancia de $1 \mathrm{~km}$ del origen y otro viajando a $100 \mathrm{~km} / \mathrm{h}$ a una distancia de $2 \mathrm{~km}$ de la misma referencia, podríamos deducir que ambos partieron de ese punto al mismo tiempo, así la evidencia empírica hace posible retrotraer el universo a un momento violento y

catastrófico de inicio, un big bang originario de todo cuanto existe incluidos tiempo y espacio, que dejó como evidencia observable una radiación de fondo cósmica, cuya fina estructura ha permitido hurgar en la creación misma del cosmos. La cosmología científica moderna parece asentarse en fuertes pilares teórico-empíricos que dan testimonio de una evolución cósmica de casi 14000 millones de años que a partir de un fuego primigenio ha dado lugar a las más inimaginables entidades celestes en constante proceso de creación y destrucción: estrellas, pulsares, quásares. Toda una fauna estelar en fulgurante evolución. Lejos del orden geométrico, del universo máquina, del universo determinista, que vislumbraron respectivamente Kepler, Newton, Laplace, el desorden y el caos se manifiestan nuevamente.

Tres escalas - nuestra banda media, la microfísica y la macrofísica-, en las que en la interpretación de Morin: "el desorden surge para reivindicar audazmente el trono que ocupaba el Orden" (Morin, [1981] 2006a: 57) y "el caos está permanentemente subyacente como infraestructura de nuestra physis" (Morin, [1981] 2006a: 78). Pero entonces, ¿cómo surge el orden?, ¿qué magia suscita la estructura del átomo, las formas maravillosas de las galaxias, la complejidad de la célula, la maravilla del cerebro y de la conciencia? Morin halla algunas pistas en disciplinas nacidas a mediados del siglo xx: la teoría de sistemas, la cibernética, la teoría de la información.

El gran teatro del mundo ya no puede concebirse en el sentido simple de la existencia de un espacio y un tiempo absolutos que cumplen la función del escenario donde se desarrolla la puesta en escena de objetos materiales como entidades que se pueden entender en su ser ontológico aislado de todo entorno: el átomo como el objeto de estudio de la física o la química, el organismo y la célula como objetos de estudio de la biología, etc. Al final, los objetos de estudio devienen en sistemas cuya explicación radica no en sus constituyentes, sino en su naturaleza organizacional. El átomo, concebido antaño como la constitución última y expresión mínima e indivisible de la materia, es un bullir de partículas, ondas, 
interacciones, campos que despliegan un comportamiento sumamente complejo, de lo cual depende toda la diversidad del mundo que conocemos. Los átomos forman moléculas, ya sea inorgánicas u orgánicas, éstas últimas se aglutinan en entidades vitales, organismos, ya sean vegetales o animales. $\mathrm{Y}$ en el nivel más alto de organización, seres humanos, sociedades, etc. La Naturaleza, nos dice Morin:

no es más que esta extraordinaria solidaridad de sistemas encabalgados edificándose los unos sobre los otros [...] el sistema ha tomado el lugar del objeto simple y sustancial, y es rebelde a la reducción a sus elementos; el encadenamiento de sistemas rompe la idea de objeto cerrado y autosuficiente (Morin, [1981] 2006a: 121-122).
La cibernética, más particular que el concepto sistémico, aunque igualmente transdisciplinar, aplicable a sistemas físicos y sociales, trata de la comunicación y el control como características básicas de los organismos vivos e imitables en las máquinas y las organizaciones. Para Morin, el elemento clave es el de retroalimentación, que rompe con la idea de causalidad lineal y que lo lleva al concepto de "recursión" o de "causalidad circular", como un proceso en el que "los 'efectos' retroactúan sobre sus 'causas" (Morin, [1988] 2006c: 111), pero que él intenta llevar más lejos considerando que es algo que revela "un proceso organizador fundamental y múltiple en el universo físico, que se desvela en el universo biológico y que nos permite concebir la organización de

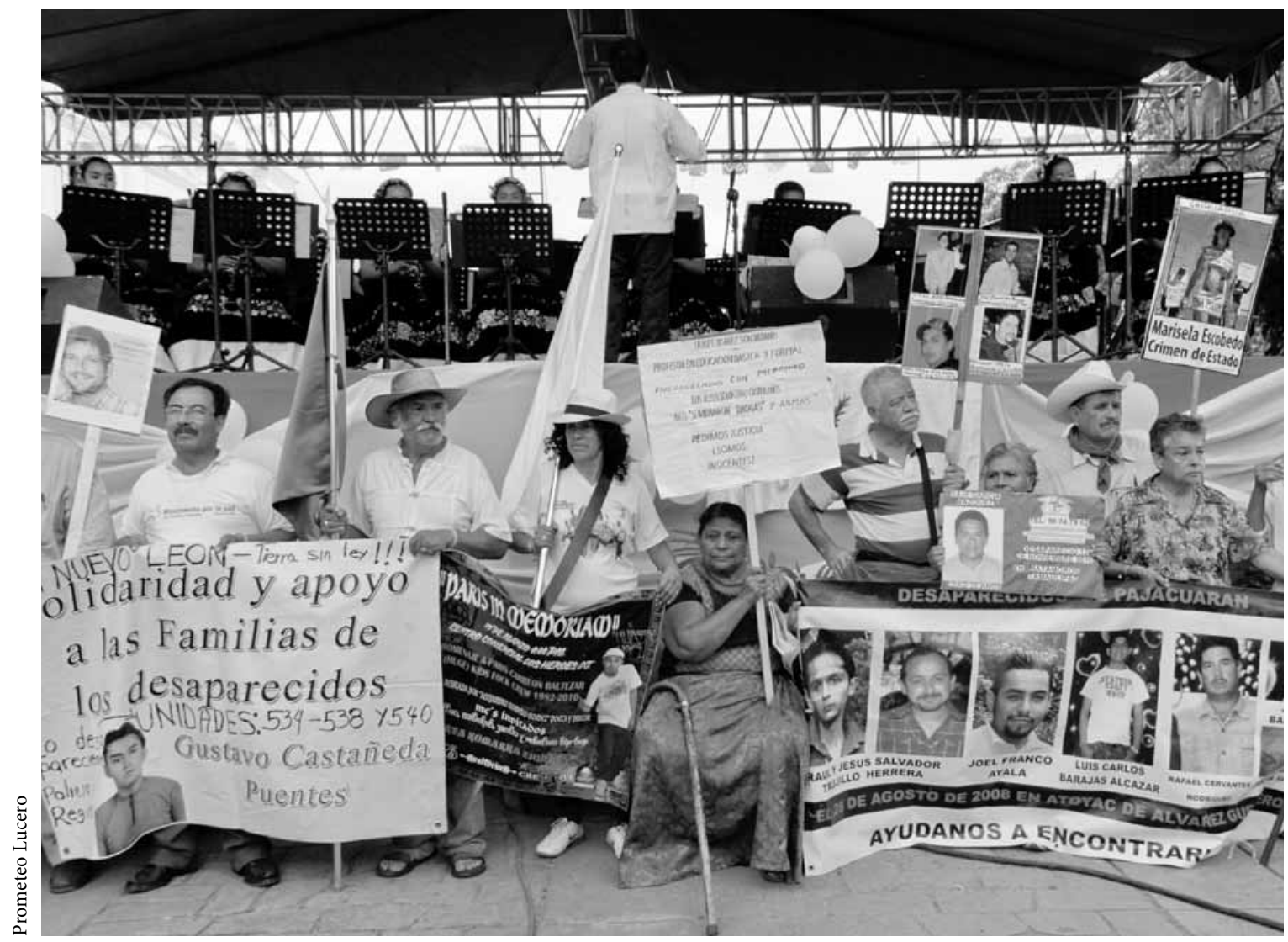

Integrantes del Movimiento por la Paz con Justicia y Dignidad en Juchitán, Oaxaca, 13 de septiembre de 2011. 
la percepción y la organización del pensamiento" (Morin, [1988] 2006c: 112).

Tanto la cibernética como la teoría de sistemas hacen uso del concepto de "información", pero esta noción es más autónoma y, según explica Morin, alcanza a enraizarse en la misma physis, en el mismo sustrato de la realidad. Ésta surge con Shannon y Weaver a mediados del siglo $\mathrm{xx}$ en un dominio práctico de interés tecnológico, sobre la manera más eficiente y económica de transmitir mensajes, que con el transcurso de las convergencias tecnológicas digitales y computacionales ha tenido un desarrollo formidable, un reto de codificación de símbolos para la generación, almacenamiento y transmisión de cosas significantes. Resulta interesante la extrapolación de esta teoría de la información al dominio biológico: el ADN, centro de la biología moderna, constituye una especie de programa computacional para la reproducción y el mantenimiento del organismo, cuyo éxito depende de una transmisión eficaz de la información. No obstante, el concepto de junto de símbolos lanzados al azar no significan nada, pero una agrupación de elementos ordenados conlleva información, como el conjunto de letras en este escrito. De ahí la definición probabilística que diera Shannon y que eventualmente se ligara, en orden inverso, con el concepto de entropía que, como vimos antes, también es una medida de probabilidad. El concepto será central en la nueva physis. Morin escribe, citando a Boulding, que "la información es la tercera dimensión básica más allá de la masa y la energía" (Morin, [1981] 2006a: 347). De esta manera, la información queda ligada con la physis pero, hay que advertirlo, con una contradicción: en tanto el cosmos en su totalidad va sufriendo la degradación, la dispersión de la energía, la muerte térmica, se organiza a la vez en formas complejas y de mayor orden manifiestas en este carácter informacional.

La virtud de estas nuevas aproximaciones del siglo $\mathrm{xx}$ es la de estudiar las características de los sistemas abiertos, a diferencia de lo que privilegiaba la ciencia clásica, que eran los sistemas cerrados, aislados. Lo

más importante aquí es la comunicación con el entorno, el intercambio de materia, energía e información con el ambiente que rodea a una entidad que se encuentra lejos de una situación de equilibrio y que da lugar a propiedades completamente nuevas. Por eso Ilya Prigogine hace hincapié en la física del no equilibrio y la posibilidad de incluir al caos y a la flecha del tiempo en las leyes de la naturaleza. Ya lo comentábamos, el tiempo es la dimensión existencial primordial y no había sido incorporada a la visión mecanicista newtoniana, pues sus leyes eran reversibles. La introducción de la segunda ley de la termodinámica fue una primera inserción del flujo del tiempo, pero sólo conducía al desorden y resultaba incompatible con la aparición de novedades - como ocurre con la teoría de la evolución darwiniana- y con la creatividad del universo. Era necesario reconocer que "la producción de entropía contiene siempre dos elementos 'dialécticos': un sentido creador de desorden, pero también un elemento creador de orden" (Prigogine, [1988] 1998: 48). La ciencia de Prigogine nos abre las puertas a la existencia de bifurcaciones, a un devenir que no se puede atrapar en un determinismo absoluto, pues la dirección tomada por un sistema puede modificarse radicalmente por cambios infinitamente pequeños en las condiciones del sistema que son imposibles de conocer y/o medir y que conducen a la generación de novedades, de nuevas estructuras, de nuevos ordenamientos. Morin recoge estas ideas:

desviación, perturbación y disipación pueden provocar "estructura", es decir, organización y orden a la vez. Es posible, pues, explorar la idea de un universo que forma su orden y su organización en la turbulencia, la inestabilidad, la desviación, la improbabilidad, la disipación energética (Morin, [1981] 2006a: 59).

La vieja physis, de carácter estático, desprovista de vida, sin posibilidad de dar lugar a nada nuevo, encerrada en su idea de materia conformadora de objetos inertes, es sustituida por un nuevo "principio inmanente de transformación y de organización" 
(Morin, [1981] 2006a: 75), donde "el caos está permanentemente subyacente como infraestructura de nuestra physis" (Morin, [1981] 2006a: 78), que lleva a "concebir un principio complejo del universo" (Morin, [1981] 2006a: 85). Estas ideas son el punto de partida de una forma de intuición moriniana, primero hacia una "ontología [...] que pone el acento sobre la relación en detrimento de la sustancia $[y]$ sobre las emergencias, las interferencias, como fenómenos constitutivos del objeto" (Morin, [1990] 2007: 76), y posteriormente hacia un paradigma de complejidad que nos permita pensar la realidad en sus múltiples dimensiones, en sus variadas expresiones y, sobre todo, hacer retornar a los "expulsados" de la ciencia clásica, pues si bien dicha exclusión sentó las posibilidades de una extraordinaria explosión de conocimientos, representó "una debilidad de mucho peso que ahora asfixia, sofoca, a la nueva y necesaria metamorfosis" (Morin, [1990] 2007: 79). Ahora damos la bienvenida a lo aleatorio, al accidente, a la creatividad, a la imaginación, al sujeto. Elementos que hasta finales del siglo XIX se consideraran la expresión misma de lo anticientífico y que empezaron a infiltrarse poco a poco ante los agotados recursos de la ciencia vieja ahora son el marco de una posible renovación, de un nuevo paradigma. No se trata, desde luego, de rechazar todo lo que la empresa científica nos ha regalado en discernimiento, en dilucidaciones extraordinarias de los enigmas del mundo, pero sí de renovar el misterio, nuestra capacidad de asombro, de aprender a vivir con la incertidumbre.

\section{CÍRCULOS DE CONOCIMIENTO}

Edgar Morin sintetiza el cambio de paradigma que cree vislumbrar de la siguiente manera:

En la visión clásica, cuando una contradicción aparecía en un razonamiento, era una señal de error. Significaba dar marcha atrás y emprender otro razonamiento.
Pero en la visión compleja, cuando se llega por vías empírico-racionales a contradicciones, ello no significa un error sino el hallazgo de una capa profunda de la realidad que, justamente porque es profunda, no puede ser traducida a nuestra lógica (Morin, [1990] 2007: 100)

Quizá podemos encontrar un buen ejemplo de esto en el intento de comprender el fenómeno de la luz. La elucidación del mismo había oscilado entre interpretaciones "corpusculares" y "ondulatorias". $\mathrm{La}$ física cuántica, a través del principio de complementariedad de Niels Bohr, nos habla de la dualidad onda-corpúsculo de la luz. Ésta se presenta como una u otra cosa según el contexto experimental que busque captar el fenómeno. Las dos descripciones son excluyentes, en el sentido de que no se manifiestan simultáneamente, y complementarias, porque la totalidad del fenómeno sólo puede entenderse por medio de la superposición de las diferentes descripciones del mismo. Si esto sucede dentro de una misma disciplina, que en el ejemplo mencionado sería la física, igual deberá ocurrir de manera transdisciplinaria, en el sentido de que podemos comprender mejor la realidad a partir de múltiples miradas que se retroalimenten y dialoguen entre sí y con la realidad misma. Este esfuerzo de comunicación entre disciplinas tendrá que ir acompañado de una dimensión epistemológica envolvente que fecunde esa convivencia y ese diálogo.

La misma física cuántica puso también su grano de arena para cambiar lo que era moneda de uso común en las ciencias naturales: olvidar que todo conocimiento es conocimiento de alguien, que el observador juega un papel importante. A su vez, otras instancias permiten reconocer que además ese alguien pertenece a una cultura. De ahí que los problemas mente-cerebro, por un lado, e individuo-sociedad, por el otro,

\footnotetext{
${ }^{3}$ La mente humana recurre a formas experimentadas en otros contextos para tratar de explicar fenómenos diferentes que pueden ser más escurridizos. Ciertamente podríamos preguntar: ¿qué hay más escurridizo que la luz?
} 


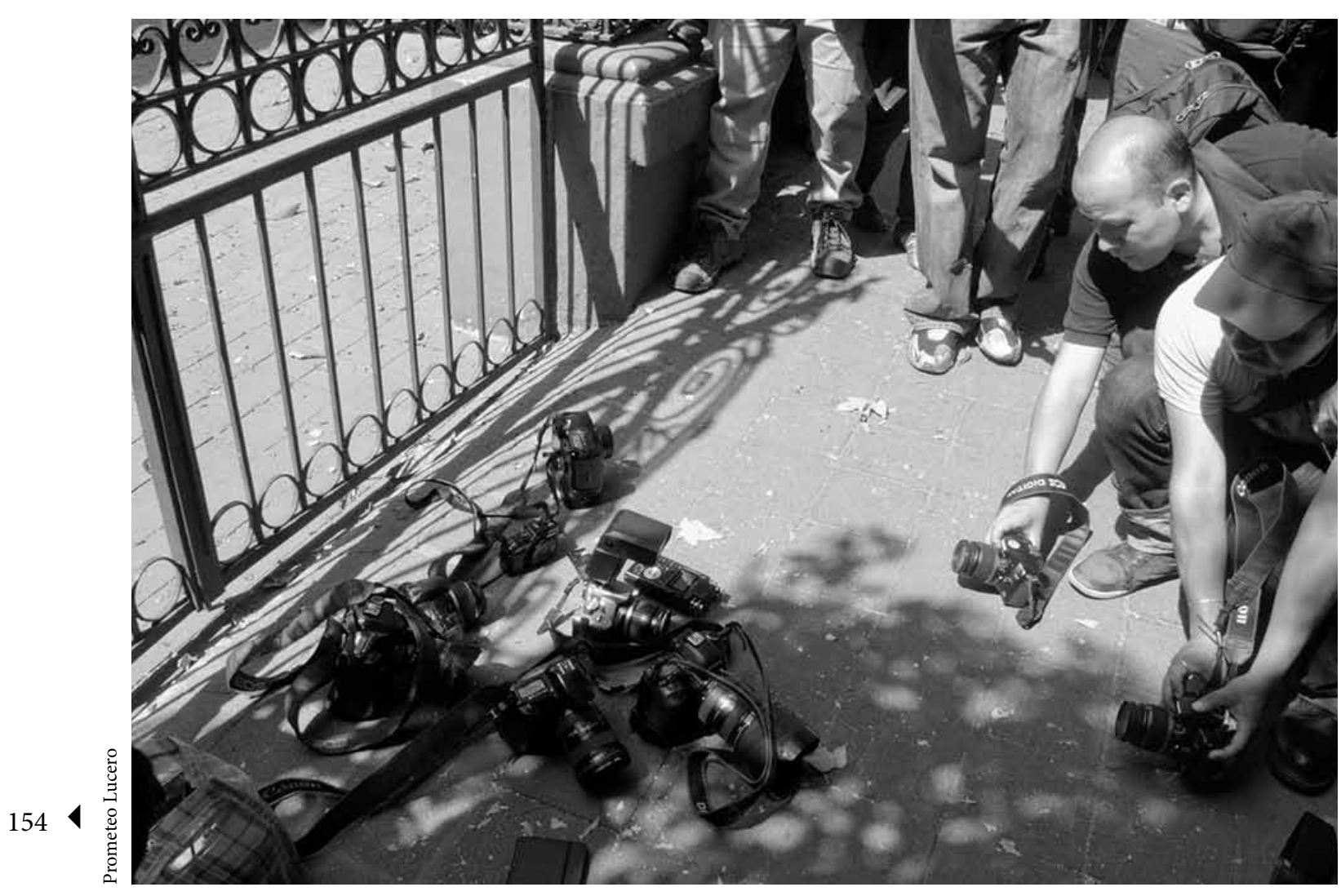

Periodistas de distintos medios de comunicación protestan por el asesinato de Regina Martínez, corresponsal de Proceso, en la representación del gobierno de Veracruz en la ciudad de México, 30 de abril de 2012.

sean centrales. ${ }^{4}$ La conciencia se nos aparece como el fenómeno más asombroso y ahora reconocemos plenamente su lazo con la realidad física y la realidad biológica. Esto nos lleva a la preocupación de Morin por encontrar conexiones y puentes entre las ciencias del hombre, las ciencias biológicas y las ciencias físicas, pues en el nuevo paradigma de la complejidad "la vida deja de ocupar un lugar intermedio entre lo físico y lo antropológico: adquiere un

\footnotetext{
${ }^{4}$ Ya que mencionamos lo que tiene que decir la física cuántica sobre esos temas, es relevante citar a manera de ejemplo respecto del tema de la relación mente-cerebro la propuesta que hace Roger Penrose en su libro Sombras de la mente, primero en el sentido de distinguir el pensamiento consciente de la mera computación, y posteriormente de investigar de qué modo la conciencia aparece a partir de la materia, el espacio y el tiempo, hurgando en la profundidad del campo mecano-cuántico (Penrose, 2007).
}

sentido amplio que se enraiza en la organización física y se despliega sobre todo lo que es antroposocial" (Morin, [1983] 2006b: 29). De ahí que la nueva physis deba dar testimonio de esa realidad compleja. Debe surgir un nuevo paradigma en el que se intente un punto de vista que cuente con el mundo y reconozca al sujeto. Este último y su conciencia tienen un sustrato biológico y físico, pero lo trascienden y desde el horizonte del mundo se interrogan sobre su ser y su ser en el mundo. Lo fundamental, las preguntas más trascendentes del ser humano nos llevaron al conocimiento científico y ahora éste debe llevarnos de vuelta a los planteamientos cardinales. Para Schrödinger, "los logros prácticos de la ciencia tienden a ocultar su auténtico sentido", que es el de conocernos mejor. No se menosprecia que la ciencia 
sea fuente de invenciones para el mejoramiento de las condiciones de vida, si bien no debemos "subestimar la tarea idealista de la ciencia” (Schrödinger, [1951] 1988: 19-20), que en palabras de Morin es la de "esclarecer la condición y la conducta humana" (Morin, [1992] 2006d: 71). Los esfuerzos de la ciencia natural en torno a esa preocupación central deben acompañarse armónicamente de nuestras demás formas de conocimiento, es decir que en "síntesis con el resto del saber [...] contribuya realmente a responder al interrogante [...] ¿qué somos?" (Schrödinger, [1951] 1988: 15). La tarea que Morin propone:

no tiene la intención de limitar el conocimiento de lo humano sólo a las ciencias. Considera literatura, poesía y artes no sólo como medios de expresión estética, sino también como medios de conocimiento [...] tiene la plena voluntad de integrar la reflexión filosófica en lo humano, pero alimentándola de los logros científicos (Morin, [2003] 2006e: 17).

Incluso, estaríamos hablando de un nuevo paradig$m a$ en el sentido de aquello que representa "la clave de todo un sistema de pensamiento", que como tal tiene repercusión en toda la acción humana, es decir, "afecta a la vez a la ontología, a la metodología, a la epistemología, a la lógica, y en consecuencia, a la práctica, a la sociedad, a la política" (Morin, [1990] 2007: 82). Siguiendo a Morin, hay que entender al hombre en su carácter físico, biológico y cultural. Para comprender nuestra naturaleza debemos transitar cíclicamente desde la esfera de la physis - que no se reduce a una supuesta materialidad del mundo, sino a un mundo de interacciones regida, estructurada, por la triada orden-desorden-organización-, que aparece en todos los niveles de la realidad, hasta la esfera de la cultura, pues "la humanidad no se reduce de ningún modo a la animalidad, pero sin animalidad no hay humanidad [y] el concepto de hombre comporta una doble entrada; una entrada biofísica, una entrada psico-socio-cultural, que se remiten la una a la otra" (Morin, [2003] 2006e: 37).
Finalmente, atendiendo al despliegue amplio de la condición humana, es imperativa la comprensión del hombre en toda su entrelazada diversidad de manifestaciones, es decir, en su carácter de sapiens, pero también en el de faber, de economicus, de demens, de ludens, y sobre todo de complexus (Morin, [2003] 2006e: 130-159).

Vemos entonces que la propuesta moriniana busca abarcar todos los campos de acción humana. Incluso para su propuesta de una ética de religación, sobre la que no profundizaremos en este ensayo, Morin propone un nuevo humanismo que, más que afirmar la dignidad del hombre y la búsqueda de su emancipación para asumir soberanamente su conformación ética e intelectual, se fundaría más bien en el reconocimiento de la fragilidad que nos caracteriza y en la fraternidad planetaria con todos nuestros semejantes. El sentido de una ética así renunciaría a cualquier pretensión de salvación, de progreso o de promesa y se adheriría más bien "a la poesía de la vida" y a una "resistencia a la crueldad del mundo y a la barbarie humana" (Morin, 2006f: 223) y buscaría voltear la vista para escrutar nuestras fuentes cósmicas, reconocernos como parte de la innovación y creatividad del universo en su proceso evolutivo y, al hacerlo, "asumir nuestro destino cósmico, físico, biológico [que] es asumir la muerte al tiempo que se le combate" (Morin, 2006f: 43). En definitiva, Morin busca puentes de comprensión desde el orbe de la physis hasta el orbe ético. Como precisa él mismo: "no se podría deducir un deber de un saber [...] la moral es verdad subjetiva y el saber pretende la verdad objetiva [...] pero la conducta moral debe tener conocimiento de las condiciones objetivas en las que se ejerce" (Morin, 2006f: 67), es decir, la razón no es privativa del conocimiento objetivo, sino que también debe actuar desde la subjetividad en un intento de dilucidar lo que debe ser dentro del orbe ético para la construcción de mundos mejores. Se trata de utilizar, como lo dijera el filósofo español José Antonio Marina (1993), una "inteligencia creadora” para alcanzar un conocimiento del ser y del deber ser. 
Ciertamente, en este intento abarcador Morin no hace alarde de originalidad: "El discurso que emprendo está ya esbozado por todas partes" (Morin, [1990] 2007: 75). Por otro lado, en su afán de articular los múltiples saberes, tiende a perderse en generalidades carentes de operatividad y en el uso de un lenguaje que más de uno calificaría de excesivamente metafórico y falto de propuesta metodológica propiamente dicha. De ahí surgen algunas de las críticas que se le han hecho. Carlos Reynoso, por ejemplo, nos dice que "el trabajo de Morin es una especificación filosófica que se encuentra muchos niveles de generalidad por encima de una posible implementación científica" (Reynoso, 2007: 45) y que por tanto habría que tomar su trabajo como punto de partida, o en todo caso como "trampolín para saltar hacia una investigación más sofisticada" (Dobuzinskis, 2004: 449) que conecte con las más actuales teorías científicas de la complejidad. Habría que estar hasta cierto punto atentos a estas críticas, pero también reconocer que en ese entretejido diatomarse en cuenta, una exploración intelectual cuya agudeza nos conduce de las preguntas más profundas del misterio de la vida, de la muerte y de la conciencia, hacia nuestra más íntima conexión espacio-temporal con el cosmos y nos permite indagar sobre el aún más profundo misterio del conocimiento, no a secas, sino del conocimiento humano, atendiendo a sus orígenes, sus posibilidades y sus limitaciones asociadas a nuestra propia naturaleza física, biológica e intelectual, caracterizada por la fragilidad y la vulnerabilidad. Habría que decir que lo aquí expuesto, por su brevedad, quizá no hace justicia a la amplísima obra de Morin, pero al menos ha intentado extraer el espíritu del pensamiento de este filósofo francés, cuyo interés principal ha sido el hombre y su condición en el mundo, pero siempre con la convicción de que la verdadera comprensión

anhelada tiene que pasar por la lucha contra la fragmentación del conocimiento que las formas de aproximación científica clásicas nos han heredado.

\section{Referencias}

Descartes, René, [1637] 1998, Discurso del método, Losada, México.

Dobuzinskis, Laurent, 2004, "Where Is Morin's Road to Complexity Going?", en World Futures: The Journal of General Evolution, vol. 60, núms. 5 y 6, pp. 433-455.

Gleick, James, 1988, Chaos: Making a New Science, Penguin Books, Nueva York.

Marina, José Antonio, 1993, Teoría de la inteligencia creadora, Anagrama, Barcelona.

Morin, Edgar, 1984, Ciencia con consciencia, Anthropos, Barcelona.

, [1981] 2006a, El método 1: la naturaleza de la naturaleza, Cátedra, Madrid.

—_, [1983] 2006b, El método 2: la vida de la vida, Cátedra, Madrid.

—_, [1988] 2006c, El método 3: el conocimiento del conocimiento, Cátedra, Madrid.

—_, [1992] 2006d, El método 4: las ideas: su hábitat, sus costumbres, su organización, Cátedra, Madrid.

—- [2003] 2006e, El método 5: la humanidad de la humanidad: la identidad humana, Cátedra, Madrid. , 2006f, El método 6: ética, Cátedra, Madrid. , [1990] 2007, Introducción al pensamiento complejo, Gedisa, Barcelona.

Penrose, Roger, 1989, The Emperor's New Mind: Concerning Computers, Minds, and the Laws of Physics, Penguin Books, Nueva York.

, 2007, Las sombras de la mente: hacia una comprensión científica de la conciencia, Crítica, Barcelona.

Prigogine, Ilya, [1988] 1998, El nacimiento del tiempo, Tusquets, Barcelona.

Reynoso, Carlos, 2007, Edgar Morin y la complejidad: elementos para una crítica, Grupo Antropocaos, Universidad de Buenos Aires, Buenos Aires.

Schrödinger, Erwin, [1951] 1988, Ciencia y humanismo, Tusquets, México.

Snow, Charles Percy, 1964, The Two Cultures: And a Second Look, Cambridge University Press, Cambridge. 